\title{
Sistemas ERP: características, custos e tendências
}

\author{
Thais Cássia Cabral Padilha \\ Oracle do Brasil \\ Fernando Augusto Silva Marins \\ Faculdade de Engenharia - Campus de Guaratinguetá - UNESP
}

\begin{abstract}
Resumo
Muitas empresas estão adotando Sistemas ERP devido a várias razões, tais como: decepção com sistemas incompatíveis, incapacidade do Departamento de Tecnologia de Informação em realizar a integração entre os sistemas existentes atualmente na empresa e outros motivos que influenciam diretamente a competitividade da Empresa. Neste contexto, este artigo apresenta as principais características de Sistemas ERP, suas vantagens e desvantagens, bem como os custos envolvidos na sua implementação. Finalmente, as tendências e o futuro de Sistemas ERP são comentados.
\end{abstract}

Palavras-chave

Sistemas ERP, características, custos de implementação, tendências.

\section{ERP systems: characteristics, implementation cost, tendencies}

\begin{abstract}
Several Companies are adopting ERP systems due to different reasons, such as: deceptions with incompatible systems, incapacity of Technology Information Department of doing integration among current systems, and other reasons which have direct influence in Company's competitiveness. In this context, this work presents the main ERP system characteristics, and the advantages, disadvantages and costs involved with its implementation. Besides this, the tendencies and the future for ERP systems are commented.
\end{abstract}

Key words

ERP systems, characteristics, implementation cost, tendencies. 


\section{INTRODUĈ̣̃O}

No atual cenário empresarial mundial, as empresas buscam cada vez mais aumentar a sua competitividade, seja pela redução de custos, pela melhoria do produto, agregando mais valor ao produto e se diferenciando da concorrência ou se especializando em algum segmento ou nicho de mercado. A competição tem escalas globais, acontecimentos em países distantes podem trazer conseqüências instantâneas para a indústria local.

Os sistemas de informação estão em evolução contínua desde que os processos produtivos e a cadeia produtiva começaram a despertar o interesse da alta administração. Em pouco tempo, houve uma evolução que consistiu no surgimento do MRP - Material Requirements Planning, passando pelo MRPII - Manufacturing Resources Planning e chegando ao Enterprise Resource Planning - ERP (STAIR, 1999).

A tendência atual da área de sistemas de informações gerenciais é de não apenas visualizar a empresa isoladamente, mas toda a cadeia de suprimento, conseguindo realizar o planejamento estratégico e tático globalmente para a cadeia, além do operacional para a empresa.

Para isso, estão sendo desenvolvidos softwares de gestão (SAUTER, 1996) - novas ferramentas para atuar tanto em uma ponta da cadeia, no caso dos clientes com o CRM - Customer Relationship Management (CHLEBA, 2001) até a outra ponta dos fornecedores com o SRM - Supplier Relationship Management (http://help.sap.com/saphelp_srm30/ helpdata/en/95/f6a93e08503614e10000000a114084/ frameset.htm).

A introdução de um ERP em uma empresa tem um impacto enorme em todas as operações que são realizadas diariamente em suas instalações. Os sistemas ERP são atraentes porque unificam a informação, pois surgiram com a promessa de resolver problemas de integração, disponibilidade e confiabilidade de informações ao incorporar em um único sistema as funcionalidades que suportam diversos processos de negócios em uma empresa (OLIVEIRA \& RAMOS, 2002).

Muitas empresas estão optando pelos pacotes ERP (Enterprise Resource Planning) devido a vários motivos, tais como: frustrações com sistemas incompatíveis, departamentos de tecnologia de informação desabilitados a prover integrações entre estes sistemas e outros que influenciam diretamente na obtenção de maior competitividade.

Além disso, algumas empresas têm, com sucesso, utilizado a implementação de sistemas ERP como uma ferramenta de apoio ao Processo de Reengenharia de Negócio (Business Process Reengineering - BPR) aplicado à Manufatura $(\mathrm{KOCH}, 2001)$.

Nesta linha, Koch (2001), apresenta algumas experiências de implementações conjuntas de BPR e ERP que têm levado a diferentes níveis de integração nas empresas em que isso foi desenvolvido; o autor finaliza afirmando que permanece como um desafio, e tarefa relevante, o entendimento de como fazer adequadamente o BPR com o uso de softwares de ERP.

De acordo com Davenport (1998) apud Nah et al. (2001), as dificuldades e a ocorrência de alta taxa de falha na implementação de sistemas ERP têm sido amplamente citadas na literatura, mas a publicação de resultados de pesquisas sobre os fatores críticos de sucesso nestas implementações tem sido rara e fragmentada. 
Tecnologia de Informação, são apresentadas características, vantagens e desvantagens, bem como uma proposta de fatores críticos e os custos de implantação de pacotes de ERP.

O artigo está estruturado como se segue. Na próxima seção são definidos os Sistemas Integrados de Gestão Empresarial e é apresentado um breve histórico com a evolução de Sistemas de Informação. Na seção 3, discute-se a arquitetura e as funcionalidades principais de um Sistema ERP. Na seção seguinte, aborda-se a Metodologia de Implantação, pontos críticos deste tipo de sistema, fatores importantes e custos envolvidos. Finalmente, a seção 5 trata de tendências de mercado e do futuro de Sistemas ERP.

\section{SISTEMAS INTEGRADOS DE GESTÃO EMPRESARIAL [ERP)}

\section{Definição de Sistema ERP}

A sigla ERP - Enterprise Resource Planning traduzida literalmente, significa "Planejamento dos Recursos da Empresa", o que pode não refletir a realidade de seus objetivos. Koch, Slater e Baatz (1999) citam: “...esqueça a parte do planejamento - ele não o faz, e esqueça os recursos, é apenas um termo de ligação. Mas lembre-se da parte da empresa. Esta é a real ambição dos sistemas ERP”.

Os sistemas ERP fornecem rastreamento e visibilidade global da informação de qualquer parte da empresa e de sua Cadeia de Suprimento, o que possibilita decisões inteligentes (CHOPRA e MEINDL, 2003).

Estes Sistemas, também chamados no Brasil de Sistemas Integrados de Gestão Empresarial, controlam e fornecem suporte a todos os processos operacionais, produtivos, administrativos e comerciais da empresa. Todas as transações realizadas pela empresa devem ser registradas para que as consultas extraídas do sistema possam refletir o máximo possível a realidade.

Pode-se dizer que o ERP é um sistema integrado, que possibilita um fluxo de informações único, contínuo e consistente por toda a empresa, sob uma única base de dados. É um instrumento para a melhoria de processos de negócios, como a produção, compras ou distribuição, com informações on-line e em tempo real. Em suma, o sistema permite visualizar por completo as transações efetuadas pela empresa, desenhando um amplo cenário de seus negócios (CHOPRA e MEINDL, 2003).

\section{Histórico - Evoluc̣ão dos Sistemas de Informação}

A partir da década de 90 , o cenário mundial e as organizações começaram a sofrer mudanças cada vez mais drásticas e rápidas. Cada vez mais pessoas lidavam com um volume maior de informações, provenientes tanto do ambiente interno, quanto do externo.

De fato, com a globalização, que vem reduzindo o protecionismo nos mercados e ampliou a concorrência externa nas empresas, houve a necessidade de se buscar novos padrões de qualidade, insistir na redução de custos e da margem de lucros.

Mais recentemente surgiu um novo elemento neste cenário macroeconômico, que foi o $e$-business, que criou novos canais de distribuição e comunicação para a cadeia de suprimentos, propiciou a abertura de novos modelos de negócios com acesso a novos mercados, tudo isso levando as empresas a repensar suas práticas em Logística devido às mudanças no comportamento dos clientes (em todos os níveis da cadeia) no que tange a exigências de prazos, custos e personalização dos produtos.

A título de ilustração do impacto do e-business, a Ford Brasil vendeu 20.000 veículos pela Internet, entre o Novo Fiesta e o Ka Street, só no primeiro semestre de 2003. Este número é cerca de $30 \%$ do total de vendas destes modelos da montadora, segundo o gerente de e-Business da Ford, Reinaldo Faga (Computerworld, 2003).

Segundo Chopra e Meindl (2003), acompanhando essa evolução dos Sistemas de Informação, houve também uma mudança na tecnologia adotada pelas empresas, que passaram de plataformas tipo mainframe para cliente/ servidor. Nesta segunda categoria de tecnologia, duas linhas de produtos têm se destacado:

(a) Aplicativos com base em navegador - onde os usuários precisam apenas de acesso à Internet e de um navegador em seu computador, pelo qual se acessa o sistema. Qualquer informação, ou análise fica disponível pelo navegador; orçamentos e armazenagem ficam em um servidor central. Essa tecnologia não requer muitos gastos com atualizações de software no computador do usuário;

(b)Fornecedores de Serviço de Aplicativos - ASP (Application Service Providers) - são hospedeiros de programas desenvolvidos por outros e alugam o uso do produto para as empresas.

O ASP é responsável pela execução dos aplicativos que o cliente aluga, incluindo sistemas ERP e alguns aplicativos analíticos, como sistemas focados em capacidades de planejamento (como exemplo, tem-se o Planejamento Avançado e Programação ou APS - Advanced Planning and Scheduling, que cria programações do que deve ser fabricado, onde, quando e como deve ser feito, considerando a disponibilidade de matéria-prima e a capacidade da fábrica) e sistemas focados no nível operacional (como exemplo, tem-se o Sistema Integrado de Controle da Produção ou MES - Manufacturing Execution System, que é semelhante ao ERP, mas centrado na produção da instalação fabril). 
Segundo Cardoso e Souza (2001), os níveis hierárquicos básicos até então (início dos anos 90), estratégico, tático e operacional, foram reavaliados e mostraram a necessidade de um quarto nível hierárquico: o do conhecimento. Este novo nível na hierarquia, apesar de ter estado sempre presente, mostrou-se crítico para o sucesso do fluxo de informações na empresa.

Esta mudança na estrutura organizacional das empresas trouxe à tona a necessidade de um novo tipo de Sistema de Informação, que conseguisse integrar todos os diferentes tipos existentes, tanto no nível das diversas áreas funcionais da empresa - como produção, marketing, finanças e recursos humanos -, quanto no nível hierárquico - operacional, do conhecimento, tático e estratégico -, de modo a realmente permitir, ou pelo menos facilitar, a criação de conhecimento a partir das informações existentes. Foi o início do surgimento dos Sistemas ERP.

De acordo com GED (1999), os sistemas ERP, ou Sistemas Integrados de Gestão Empresarial, passaram a ser largamente utilizados na década de 90 , dentre outros motivos devido ao acirramento da concorrência e à globalização, evidenciando a necessidade de ferramentas mais aprimoradas para a gestão das empresas. Além dos problemas já mencionados, o bug do milênio fez com que muitas empresas, ao invés de fazer a manutenção em seus antigos sistemas e continuar a desenvolvê-los internamente, optassem pela adoção de um sistema ERP, complementa Davenport (1998).

Os sistemas ERP surgiram (CORRÊA et al., 1999) a partir da evolução dos sistemas MRP e MRP II, respectivamente, Planejamento das Necessidades de Materiais (Materials Requirement Planning) e Planejamento dos Recursos de Manufatura (Manufacturing Resources Planning).

Ao módulo básico de cálculo de necessidades de materiais do MRP, foram agregados novos módulos, programação-mestre da produção, cálculo grosseiro de necessidades de capacidade, cálculo detalhado de necessidade de capacidade, controle do chão de fábrica, controle de compras, planejamento de operações e vendas, dando origem ao MRP II, que passou a atender às necessidades de informação para a tomada de decisão gerencial sobre todos os recursos de manufatura.

$\mathrm{Na}$ seqüência, novos módulos foram agregados ao MRP II, como por exemplo Gerenciamento dos Recursos Humanos, Vendas e Distribuição, Finanças e Controladoria, ultrapassando os limites da manufatura, percorrendo toda a empresa e chegando ao seu estágio atual de desenvolvimento, caracterizando um Sistema
ERP. A Figura 1 apresenta o caminho percorrido do MRP ao ERP, observando a estrutura de cada estágio bem como sua evolução.

Não existem registros precisos de quando exatamente os sistemas ERP foram criados e a partir de quando a palavra ERP passou a ser utilizada. Segundo diversas pesquisas, os ERP's tiveram suas raízes na Europa e na indústria de manufatura, sendo que em 1979 a companhia alemã SAP (Systeme, Anwendungen, und Produkte in Datenverarbeitung - Sistemas, Aplicações e Produtos em Processamento de Dados) lançou o R/2. Nessa mesma época a IBM (International Business Machine) oferecia o Sistema COPIX , ambos com as características de integração típicas do que hoje se conceitua como Sistemas ERP.

\section{ARQUITETURA E PRINCIPAIS FUNCIONALIDADES DE UM ERP}

A partir de consulta à ampla bibliografia sobre sistemas ERP, incluindo Chopra e Meindl (2003) e Nah e Lau (2001), pode-se identificar alguns pontos importantes acerca da sua arquitetura e funcionalidades:

(a) Possuem uma arquitetura de software que facilita o fluxo de informações entre todas as atividades da empresa. São um amplo sistema de soluções e informações;

(b) Através de um banco de dados único, operam em uma plataforma comum que interage com um conjunto integrado de aplicações, consolidando todas as operações do negócio em um simples ambiente computacional;

(c) Suas funcionalidades representam uma solução genérica que reflete uma série de considerações sobre a forma como as empresas operam em geral. Para flexibilizar sua utilização em um maior número de empresas de diversos segmentos, os sistemas ERP são desenvolvidos de forma que a solução genérica possa ser personalizada em um certo grau.

Uma das fases anteriores à implementação de um ERP é o desenho da nova arquitetura de processos da empresa. Para Martins e Bremer (2002), a integração e a visão por processos de negócios surge como meio potencializador para alcançar a eficiência e a sincronia das empresas no mercado competitivo global.

Nesta análise de processos, existem duas possibilida- 
des a serem seguidas, a reengenharia e/ou o redesenho de processo: no processo de reengenharia, da forma concebida por Hammer e Champy (1994), parte-se de uma "folha em branco", modelando-se todos os processos; já pelo método de redesenho de processo, segundo SCHEER (1998), realiza-se uma remodelagem considerando os processos existentes e o conhecimento de seus executores.

Scheer e Habermann (2000) afirmam, ainda, que o processo de implementação deve envolver a análise dos processos atuais do negócio e, principalmente, a possibilidade de modificá-los posteriormente.

Para Vernadat(1996), a modelagem de processos tem por finalidade obter: uniformização do entendimento da forma de trabalho, gerando integração; análise e melhoria do fluxo de informações; explicitação do conhecimento sobre os processos, armazenando, assim, know-how organizacional; realização de análises organizacionais e de indicadores (processos, financeiros e outros); e realização de simulações, apoiando a tomada de decisões.

Rozenfeld (1999) considera que a modelagem de processos de negócios "compreende um conjunto de atividades realizadas na empresa, associadas às informações que manipula, utilizando os recursos e a organização da empresa. Forma uma unidade coesa e deve ser focalizado em um tipo de negócio, que normalmente está direcionado a um determinado mercado/cliente, com fornecedores bem definidos".

Figura 1: Estrutura conceitual dos sistemas ERP e sua evolução desde o MRP.

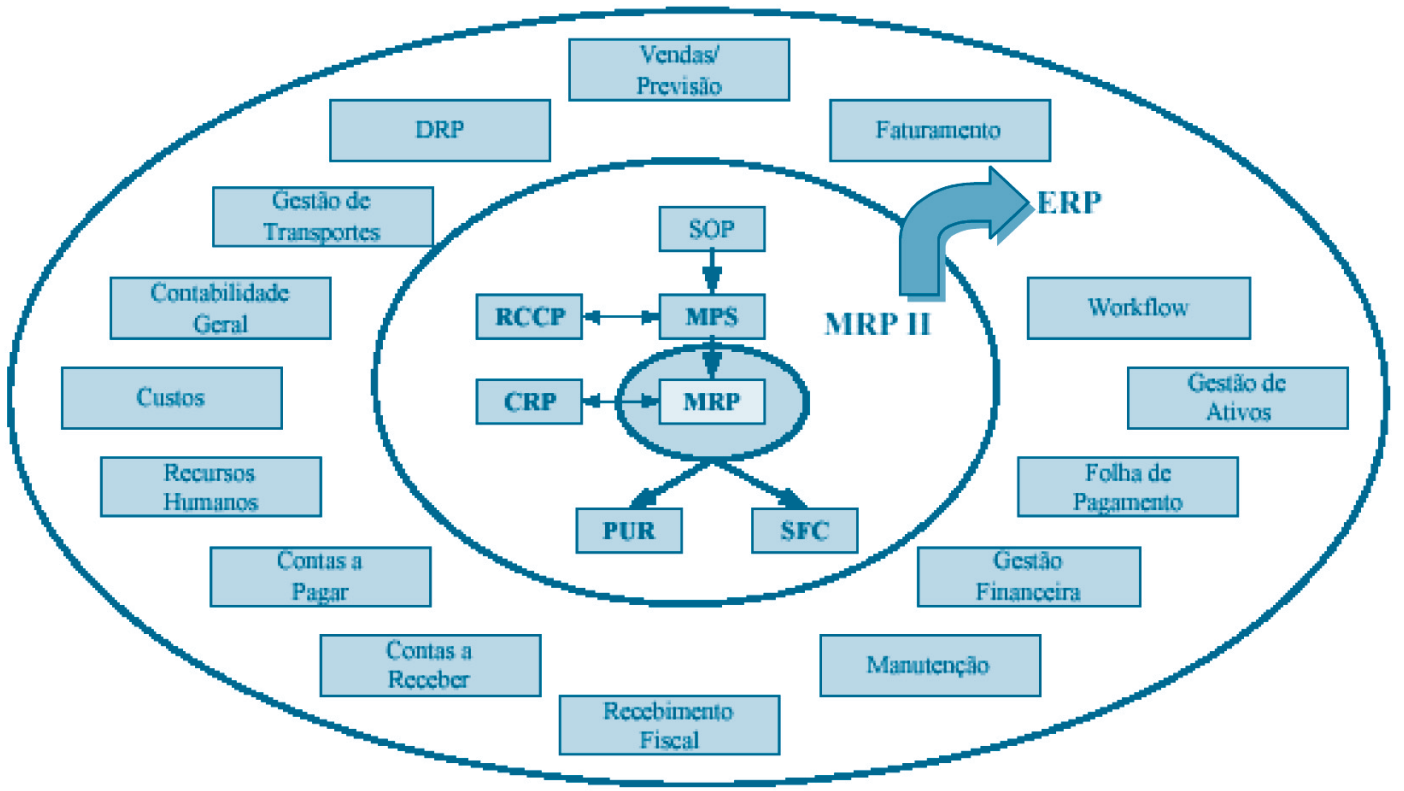

\begin{tabular}{|l|l|}
\hline DRP & Planejamento de Recursos de Distribuição \\
\hline SOP & Planejamento de Vendas e Operações \\
\hline RCCP & Planejamento Grosseiro da Capacidade \\
\hline CRP & Planejamento Detalhado da Capacidade \\
\hline PUR & Controle de Compras \\
\hline SFC & Controle de Chão de Fábrica \\
\hline MPS & Planejamento-Mestre da Produção \\
\hline MRP & Planejamento de Necessidades de Materiais \\
\hline MRP II & Planejamento de Recursos de Manufatura \\
\hline
\end{tabular}

Fonte: Adaptado de Corrêa et al. (1999, p. 350). 
A utilização de sistemas ERP otimiza o fluxo de informações e facilita o acesso aos dados operacionais, favorecendo a adoção de estruturas organizacionais mais enxutas e flexíveis. Além disso, as informações tornamse mais consistentes, possibilitando a tomada de decisão com base em dados que refletem a realidade da empresa.

Um outro benefício da sua implantação é a adoção de melhores práticas de negócio, apoiadas pelas funcionalidades dos sistemas, que resultam em ganhos de produtividade e em maior velocidade de resposta da organização.

Na Figura 2, Davenport (1998) apresenta as funcionalidades dos sistemas ERP separando-as em funções internas (back-office), composta por recursos humanos, manufatura e finanças, e funções externas (front-office), composta por vendas e serviços, além da tecnologia e do chamado Gerenciamento da Cadeia de SuprimentosSCM (Supply Chain Management).

Os dados utilizados por um módulo são armazenados na base de dados central para serem manipulados por outros módulos. Os módulos citados na Figura 2 estão presentes na maioria dos sistemas ERP. Além deles, alguns sistemas ERP possuem módulos adicionais, tais como: Gerenciamento da Qualidade, Gerenciamento de Projetos e Gerenciamento de Manutenção, entre outros.

\section{Metodologia de Implantação}

Segundo Koch, Slater e Baatz (1999), existem três principais maneiras de implantar o ERP:

(a) Substituição Total e Conjunta (Big Bang) - Neste tipo de implantação, que é o mais ambicioso e difícil método de implantação, as empresas substituem todos os sistemas legados ao mesmo tempo e implantam um único sistema ERP por toda a empresa. Embora esta metodologia de implantação tenha predominado para as primeiras implantações, poucas empresas tiveram a ousadia de utilizála posteriormente.

Figura 2: Funcionalidades dos sistemas ERP — Fonte: Davenport (1998).

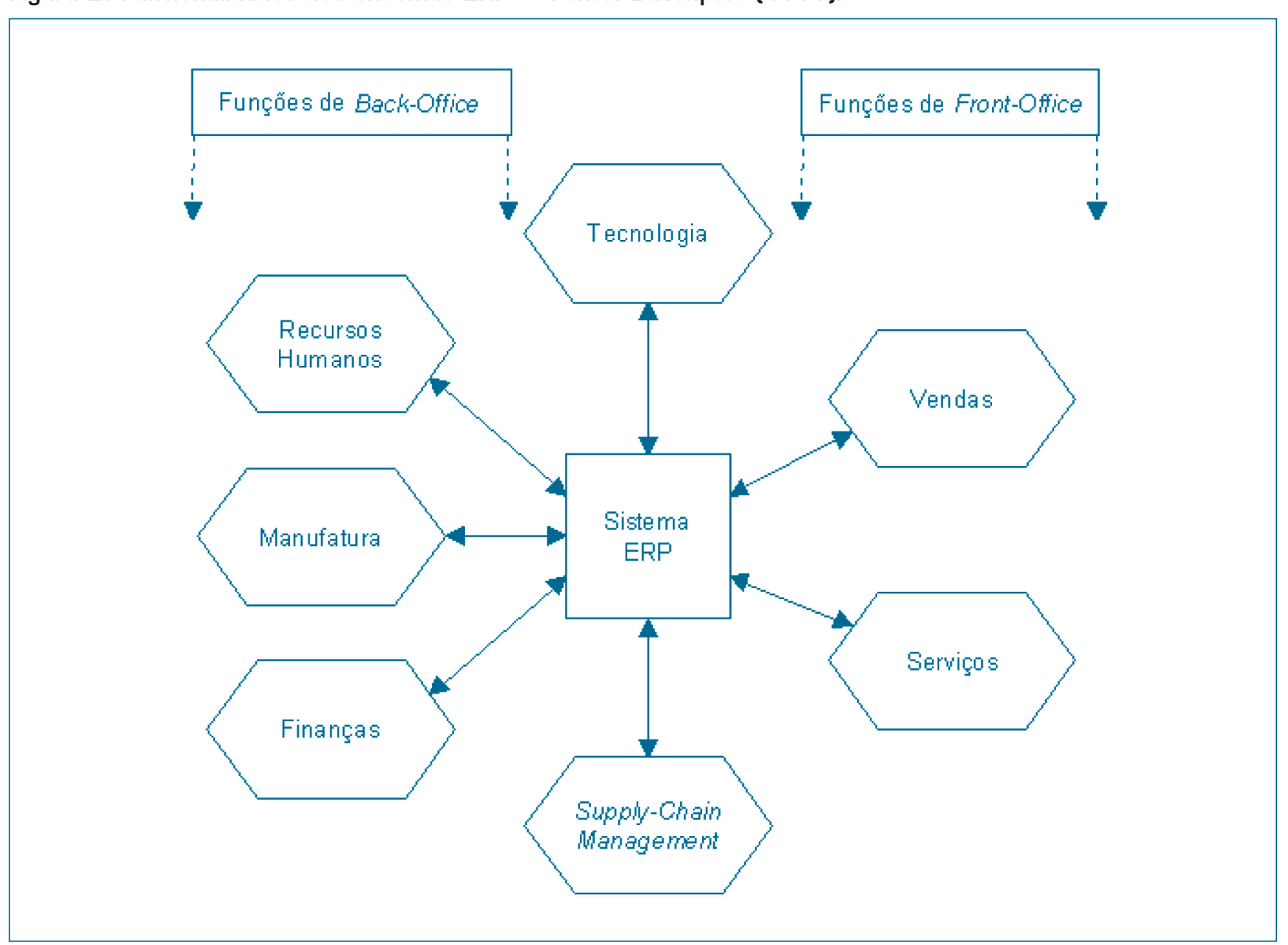


Nesta metodologia é necessário mobilizar e paralisar toda a empresa e implantar todo o sistema de uma única vez, o que exige um grande esforço da empresa, pois ninguém possui experiência em utilizá-lo, portanto não se consegue avaliar se o seu funcionamento está correto. (b)Estratégia de Franquias (Franchising) - Esta metodologia é utilizada na maior parte das implementações em empresas que não possuem muitos processos em comum entre suas unidades operacionais.

Sistemas ERP independentes são instalados em cada unidade, enquanto os processos comuns, como atualização de livros fiscais, são interligados entre as empresas. Em muitos casos, cada unidade operacional possui sua própria "instance" para o ERP (o que significa sistemas separados e banco de dados independentes).

Os sistemas se comunicam apenas para compartilhar informações necessárias para a empresa avaliar seu desempenho e a participação de cada unidade operacional; ou para procedimentos que não variam entre as unidades, como as políticas de benefícios dos funcionários.

Em outro trabalho, os autores Padilha et al. (2004), consideram e analisam empresas que utilizaram esta metodologia de implementação, com respeito ao tempo de implantação de sistemas ERP frente aos vários fatores que podem ter influência.

(c) Método "Slam-dunk" - Neste método, o ERP define o planejamento de alguns processos-chaves, como os processos financeiros. Este método é utilizado, normalmente, em empresas pequenas que esperam crescer com o ERP.

O objetivo, neste caso, é implantar o ERP rapidamente e seguir os processos de reengenharia pré-modelados pelo sistema ERP. Poucas vantagens são conhecidas para implantar o ERP para substituir um sistema legado em processos específicos, já que o ERP é mais caro e os benefícios obtidos são muito reduzidos.

\section{Pontos críticos do ERP}

Alguns pontos e características importantes dos sistemas ERP devem ser cuidadosamente analisados no momento da aquisição e implantação dos mesmos:

(i) Eles são pacotes comerciais desenvolvidos a partir de modelos-padrões de processos, que não são específicos para uma determinada necessidade, e sim genéricos, podendo a empresa compradora do sistema adequar-se ou não a eles.

Davenport (1998) afirma que "é o fornecedor que define o que é melhor, e não o cliente. Porém, em alguns casos as definições do sistema podem atender aos objetivos da empresa".

(ii)Eles integram todas as áreas da empresa, sendo este um grande ganho na utilização destas ferramentas. A empre- sa obtém integridade e confiabilidade nas informações adquiridas através do sistema, pois a entrada de um dado ocorre uma única vez dentro do sistema, que a partir de então passa a atualizar automaticamente todos os módulos necessários.

(iii)Eles permitem a adequação das funcionalidades existentes no sistema às da empresa através do processo de parametrização. Este processo consiste na definição de diversos valores que são introduzidos no sistema com o intuito de dimensionar o perfil da empresa e o comportamento do sistema.

(iv) Eles possibilitam o processo de personalização ("customização") de determinados processos de software que não se adaptam de maneira nenhuma à empresa, mesmo fazendo uso da parametrização.

A personalização é a adaptação do sistema às necessidades específicas da empresa, sendo necessário intervir com programas ou rotinas que se integram ao ERP.

Muitas atividades da empresa não são contempladas pelo sistema, não bastando apenas configurá-lo através de parâmetros. Esta etapa nem sempre é realizada pela produtora do ERP, muitas vezes uma consultoria homologada e conhecedora da solução é contratada para este trabalho.

(v) Eles possuem custos elevados, destacando-se os custos de hardware e infra-estrutura computacional, de aquisição da licença de uso do ERP, de treinamento e consultoria para a implantação.

Um sistema de ERP apresenta muitas complexidades, sendo que sua implantação deverá ser realizada por profissionais que conheçam não somente o negócio da empresa, como também a solução escolhida. Geralmente as empresas optam por contratar consultores especializados no produto escolhido.

Também os usuários dos vários departamentos deverão passar por um período no qual os esforços serão duplicados, uma vez que o trabalho deverá ser realizado paralelamente no sistema antigo (mesmo que manual) e no novo. Os custos da implantação serão abordados com maiores detalhes na próxima seção do trabalho.

(vi) Os sistemas ERP desenvolvidos em outros países, adaptam-se à realidade brasileira no que diz respeito às obrigações legais, através do processo chamado de localização. Pelo fato destas implementações representarem mudanças radicais nos sistemas, este é um ponto que deve ser muito bem avaliado.

(vii) Os fornecedores de sistemas ERP liberam periodicamente versões atualizadas (upgrades) que agregam melhorias, correções de problemas e erros do sistema. Este processo de atualização deve ser flexível e permitir a adequação da nova versão com possíveis personalizações efetuadas no produto.

(viii) Os sistemas ERP forçam, na maioria das vezes, altera- 
ções nos processos produtivos e administrativos, pois é necessária tanto a adaptação do sistema aos processos da empresa, como a adaptação da empresa a determinados processos do sistema.

Estas alterações são complexas e podem causar, no início, uma série de inconvenientes, até que todos estejam adaptados à nova realidade. É válido ressaltar também que estas alterações de processos devem estar em conformidade com as estratégias da empresa e seus objetivos de longo prazo, merecendo, portanto, grandes cuidados em sua implementação.

(ix) O ERP tem impacto sobre os recursos humanos da empresa, pois as pessoas terão que se preocupar com o processo como um todo e não apenas com a sua atividade específica. Devido à integração do sistema, um problema de uma área poderá se alastrar rapidamente para outros departamentos, existindo o risco de chegar a afetar toda a empresa.

O perfil dos profissionais muitas vezes será alterado, uma vez que se exigirá multidisciplinariedade e conhecimentos que nem sempre os atuais funcionários possuem.

A empresa deverá optar por reciclar seus profissionais, ou às vezes substituí-los.

Esta última alternativa é reforçada também pelo fato de que a partir da automação e, mais do que isso, da integração entre os processos muitas atividades que eram realizadas manualmente, ou no sistema anterior, não serão mais necessárias.

Muitas vezes, pode ocorrer resistência interna à adoção do ERP, devido à desconfiança de perda de emprego, ou de poder, uma vez que haverá maior compartilhamento da informação.

(x) Sistemas ERP apresentam dificuldades no cumprimento de prazos de instalação e orçamentos, devido a: resistência por parte das pessoas, rotatividade dos funcionários que foram treinados no novo sistema ou que dominam o negócio da empresa, qualidade dos recursos humanos internos e da equipe de consultoria contratada, limitações inerentes ao próprio produto ERP escolhido e dificuldade de integrar o ERP com outros sistemas existentes dentro da empresa ou corporação. Todos estes fatores não podem ser corretamente previstos com antecedência, no momento de elaboração dos cronogramas e orçamentos, e, por mais que se possa inserir margens de segurança, eles podem comprometer a credibilidade do projeto.

Os sistemas ERP são ferramentas extremamente caras e de difícil implementação se comparadas aos sistemas desenvolvidos alguns anos atrás. Deste modo, as justificativas de retornos de investimento são também bastante difíceis de serem defendidas.
Talvez os maiores problemas encontrados nas análises de investimentos sejam as dificuldades de mensuração das variáveis intangíveis, como a velocidade do fechamento de um balanço, a integração e a confiabilidade das informações, que se alteraram significativamente com o uso de ferramentas ERP.

\section{Fatores importantes para a implantação}

Apesar das dificuldades citadas, alguns fatores podem garantir o sucesso da implementação. Nah et al. (2001) apresentam e discutem uma lista de 11 fatores que eles consideram críticos para o sucesso de uma implementação de ERP.

stemas ERP controlam e fornecem

suporte a todos os processos acionais, produtivos, administrativos e comerciais da empresa.

Aqui, a partir da experiência de uma grande empresa de consultoria na área de Tecnologia de Informação, está se propondo uma lista de 10 fatores; estes fatores foram os mais importantes na prática, no entender de componentes de várias equipes de profissionais, da referida empresa, que vivenciam há algum tempo implementações de sistemas ERP:

1. Obter a participação ativa da alta gerência (Commitment);

2. Implementar o gerenciamento de mudanças buscando reduzir o "medo" dos usuários pouco informados;

3. Identificar os Usuários-chave, que são indispensáveis em seus respectivos departamentos;

4. Escolher com segurança para Gerente do Projeto (Gerente-Usuário) um profissional experiente e respeitado, de modo a descaracterizar o ERP como um sistema da área de informática, e sim como um redesenho do modelo de gestão;

5. Planejar e realizar treinamentos;

6. Definir claramente os diversos papéis na implementação do sistema, através da união de conhecimentos e esforços para o alcance do sucesso;

7. Adaptar o sistema à empresa e vice-versa, refletindo sobre a realidade atual da empresa ou a utilização das melhores práticas (best-practices);

8. Escolher a consultoria adequada (know-how);

9. Garantir a qualidade (Quality Assurance);

10. Simplificar em todos os sentidos: na definição de modelos, no desenho da solução e na própria implementação do sistema. 
Pode-se verificar que alguns dos fatores $(1,2,4,5$ e 10) aqui propostos coincidem com alguns daqueles 11 elencados por Nah et al. (2001) e também por Akkermans e van Helden (2002). A idéia é que as estas listas se complementem, servindo como uma referência para aqueles que estejam se preparando para implementar uma solução de ERP.

\section{- RP é sistema integrado, com fluxo de informações único, contínuo, consistente por toda a empresa e base de dados única.}

Uma alternativa encontrada pelos fornecedores de ERP para reduzir o valor do TCO, na tentativa de investir em pequenas e médias empresas, é a utilização dos ASP (Application Service Providers) - Fornecedores de Serviços de Aplicativos.

A estratégia consiste em criar centros tecnológicos, com grande infra-estrutura de hardware e instalações de software, através dos quais as empresas alugam o hardware, as instalações do ERP e toda a manutenção necessária para o aplicativo. Com esta estratégia, os investimentos necessários para a implantação do ERP apresentam uma sensível redução.

Embora diferentes empresas op-

Em um processo de implementação, o primeiro passo é determinar o escopo do projeto e a nova arquitetura de processo. Atualmente, durante esta definição, é comum utilizar-se o enfoque da reengenharia de Hammer e Champy (1994), ou seja, parte-se de uma folha em branco e tenta-se adaptar o sistema ao processo da empresa.

Ogura e Marins (2003) apresentam uma proposta de arquitetura de processos que segue a lógica de informação de um ERP para diminuir algumas fases da implementação de um sistema de informação integrado, apresentando suas características, vantagens e desvantagens dessa nova proposta de arquitetura de processos. Esta arquitetura é a adotada, atualmente, pela mesma empresa de Tecnologia de Informação que serviu com base para o desenvolvimento das propostas aqui descritas.

\section{Custos do ERP}

Wagle (1998) recomenda que a decisão de implantar o ERP só deve ser tomada com base em um fluxo de caixa positivo, pois tratam-se de projetos nos quais o período de retorno do investimento (payback) é muito longo e o investimento muito grande.

Uma empresa de consultoria realizou um estudo tentando encontrar o custo total de aquisição do ERP, TCO (Total Cost of Ownership), incluindo hardware, software, profissionais envolvidos, serviços, e custos internos. Os números do TCO incluem a instalação do software e sua manutenção durante dois anos, período em que os custos de manutenção, atualização e otimização do software à empresa são realmente sentidos.

$\mathrm{Na}$ avaliação de 63 empresas, feita por empresa de classe mundial na área de Tecnologia de Informação, incluindo pequenas, médias e grandes indústrias, o valor médio encontrado para o TCO foi de 15 milhões de dólares (sendo o valor mais alto 300 milhões de dólares e o mais baixo 400.000 dólares). Outra estatística é o valor de $\$ 53,32$ dólares por usuário durante o mesmo período. tem por diferentes maneiras de implementação e níveis de orçamentos para os projetos, de acordo com pesquisas realizadas por Koch, Slater e Baatz (1999), diversos custos poderão não ser bem estimados, alguns deles encontram-se descritos abaixo:

a) Custos de Treinamento: é o item mais exclusivo com relação aos custos envolvidos na implantação de um sistema ERP, pois seu orçamento inicial sempre se encontra abaixo das reais expectativas. Os custos de treinamento são altos porque os recursos humanos envolvidos necessitam aprender uma nova série de processos, além da nova interface de software.

b) Custos de Integração e testes entre o pacote ERP instalado e os outros softwares corporativos existentes na empresa: devem ser estudados caso a caso e ser encontrada uma solução para a correta integração. Esta solução pode ser baseada em personalização do ERP, ocasionando custos não estimados no orçamento inicial.

c) Os Custos das Conversões de Dados: estão relacionados às informações corporativas, tais como registros de fornecedores e clientes, produtos, movimentos em aberto e outros que serão migrados dos sistemas existentes para o novo sistema.

Normalmente as empresas negam que estes dados se encontram com problemas ou são inconsistentes, mas o que ocorre normalmente são inúmeros problemas no processo de adequação às necessidades e modelos exigidos pelo ERP. Logo, os custos não são estimados para este tipo de trabalho e dificuldades que geralmente ocorrem no processo.

d) Custos com Horas de Consultoria: quando não planejados pelos usuários, tornam-se extremamente difíceis de estimar.

Para evitar este tipo de problema, as empresas devem identificar os objetivos para cada parceiro contratado, e este ser cumprido enquanto o pessoal interno é treinado, além de estabelecer medidas no contrato dos consultores que obriguem o aporte de conhecimento a um número determinado 
de pessoas internas da empresa, para que se tornem multiplicadores dentro do projeto como um todo.

e) Custos com Pessoal: sabe-se que o sucesso da implantação de um sistema ERP depende das pessoas envolvidas, que devem ser as melhores, com conhecimento aprofundado do negócio, e as mais brilhantes, com conhecimento de tecnologia da informação.

O software é demasiado complexo e as mudanças no negócio são drásticas, tendo que muitas vezes a empresa optar por substituir boa parte do seu quadro de pessoal gerando custos não mensurados.

A maioria das empresas pretende tratar a implementação do ERP como um outro projeto de software qualquer; mas, uma vez que o sistema é instalado, o time de trabalho não irá de maneira alguma retornar às atividades anteriores do seu dia-a-dia, pois se tornam recursos valiosos devido a sua intimidade com o projeto.

Essas pessoas acabam conhecendo mais sobre o processo de vendas do que os próprios vendedores e mais sobre o processo de manufatura que os colaboradores da área. Infelizmente, as empresas não planejam a atuação destes recursos humanos no período pós-implantação, e acabam tendo que contratar novos colaboradores logo após o início de operação do ERP.

f) Retorno do investimento - ROI (Return of Investment): um dos grandes enganos que a gerência pode cometer, é esperar que a empresa recupere os valores gastos com a implantação do sistema ERP tão logo a aplicação seja instalada e operacionalizada. A maioria das empresas não obtém retorno do investimento enquanto não executar a solução por algum tempo, incluindo melhorias nos processos de negócio que foram afetados pelo sistema.

\section{Tendências de Mercado para o ERP}

Dentre as principais tendências e novidades incorporadas pelos principais fornecedores de ERP, pode-se destacar:

(i) Foco nas Empresas de Pequeno e Médio Porte (Small/Middle Market): Atualmente, especialmente no Brasil, o principal alvo das produtoras de sistemas ERP é o chamado "small/middle market", composto por empresas de pequeno e médio portes.

A classificação do que é uma empresa média varia muito de acordo com o fornecedor de ERP, mas de forma geral engloba as empresas com faturamento anual na faixa entre U\$\$ 10 milhões e US\$ 300 milhões.

Algumas empresas fornecedoras de ERP, que realizavam somente vendas diretas, realizaram parcerias com outras empresas (muitas vezes brasileiras) para realizar vendas através de outros canais, procurando aumentar, assim, sua capilaridade.

$\mathrm{O}$ valor a ser cobrado de uma empresa de pequeno e médio porte não será o mesmo de uma empresa de grande porte, decorrendo deste fato uma tendência de queda nos atuais níveis de preços dos sistemas ERP.

(ii) Internet: Uma grande tendência entre os fornecedores de ERP é a gradual incorporação de módulos que possam ser operacionalizados via Internet, permitindo a prática do comércio e outras práticas empresariais, por meio eletrônico (e-business).

Outra funcionalidade que está sendo agregada aos sistemas ERP são os módulos de e-procurement, que visam auxiliar os departamentos de compras e os processos de cotações, realizando a procura por fornecedores pela Internet, e dando suporte a todo este processo.

(iii) Business Intelligence (BI): é um termo genérico para aplicações, plataformas, ferramentas e tecnologias que suportam o processo de exploração de dados de negócio e análise de suas correlações e tendências. Aplicações de BI conferem às empresas meios para coletar e preparar dados com o objetivo de facilitar a geração de relatórios, análises e tomada de decisão.

Segundo estimativas do Instituto de Pesquisa Gartner Group, os gastos com BI chegarão a US \$ 8,4 bilhões em 2002 (COMPUTERWORLD, 1999). É inegável, portanto, a sua importância, sendo que todos os principais desenvolvedores de ERP ou já implementaram ferramentas de BI, ou as estão implementando.

Muito já se comentou na área de tecnologia da informação a respeito de grandes depósitos de dados (Data Warehouses), e sobre ferramentas de extração (Data Mining) destes dados, mas antes da disseminação dos ERPs, as bases para a implementação destes conceitos e ferramentas não possuíam a viabilidade hoje existente.

(iv) Supply Chain Management - SCM: ou gerenciamento da cadeia de suprimentos, é o nome do recurso que permite a integração de uma empresa com as demais organizações envolvidas no processo produtivo (clientes e fornecedores), buscando otimizar o funcionamento como um todo, com reduções de custos e ganhos de produtividade e qualidade.

Todos os principais sistemas ERPs do mercado já incorporaram funcionalidades relacionadas com a cadeia de suprimentos (Supply Chain), vendendo a idéia que após a integração dos processos internos da empresa, surge a necessidade de se integrar toda a cadeia.

Estes recursos apóiam-se fortemente na Internet, uma vez que com a evolução da globalização as relações comerciais ultrapassam as fronteiras dos países, o que torna a Internet um meio de comunicação extremamente barato e viável para este tipo de aplicação.

Pode-se ilustrar essa situação por meio de um exemplo simples: após a identificação da demanda do cliente, o ERP indica que existe uma necessidade de material e é 
criada uma ordem de compra contra determinado fornecedor; havendo a integração dos ERPs da cadeia de suprimentos, esta ordem é enviada ao ERP do fornecedor como um pedido de venda; este fluxo de informações permite que o próprio cliente alerte ao fornecedor, através de seu ERP, sobre demandas não-programadas.

(v) CRM (Customer Relashionship Management): ou gerenciamento das relações com o cliente, está assumindo um papel muito importante nos departamentos de marketing, que também utilizam a expressão marketing de relacionamento para os conceitos apoiados por esta nova ferramenta.

Trata-se da operacionalização do "DataBase Marketing", no sentido de, através da base transacional e de todas as informações disponíveis sobre os clientes, realizar análises que permitam um atendimento diferenciado, identificando necessidades e tendências de grupos de consumidores, além de facilitar a fidelidade dos clientes.

Os módulos de CRM podem incorporar também a automação da força de vendas, atualizando "notebooks" ou simples agendas eletrônicas, suporte ao "call center", telemarketing e vendas via internet, entre outras funcionalidades.

\section{Futuro do ERP}

A grande base de dados de sistemas ERP, depois de instalada, pode ser manipulada por várias lógicas. Para determinadas empresas, a lógica de MRP II (CORRÊA et al., 1999) pode ser a mais interessante para determinada fábrica ou setor. Já para outra fábrica ou setor, pode ser mais interessante adotar uma lógica de programação finita.

A partir do banco de dados, com os algoritmos adequados embutidos nos vários módulos disponíveis, será possível utilizar as lógicas mais adequadas para sua manipulação, para as diversas realidades encontradas de uma empresa que adote os sistemas ERP do futuro.

Segundo Corrêa et al. (1999), no futuro, os módulos migrarão para uma situação "plug-in"; por exemplo, se for necessário um módulo com algoritmos de programação finita, o módulo se conectará a ele, e fará uso da base de dados para gerar sugestões da ação mais adequada às necessidades particulares em questão.

Corrêa et al. (1999) acrescentam ainda que é "importante frisar que esta não é uma situação que encontramos hoje perfeitamente embutida em nenhum dos ERP's disponíveis no mercado". Entretanto, há razões para se crer que, num futuro não muito distante, ter-se-á este tipo de configuração nas soluções de software mais avançadas.

Neste sentido, é importante destacar que é falso o temor de algumas empresas sobre o ERP ser um esforço em vão, e que uma nova lógica possa surgir tornando obsoleta a solução adotada no momento. Por se tratar basicamente de uma grande base de dados, esta será sempre necessária, qualquer que seja a lógica que se use para manipular os dados que ela contém.

A implantação de sistemas ERP é normalmente complexa, e sua duração pode chegar até três ou quatro anos. Por este motivo, na maioria das implantações, o sistema é dividido em módulos, e apenas alguns módulos são implementados em cada etapa.

Segundo vários autores, entre eles Davenport (1998), a definição de prazo destes projetos é um dos fatores mais críticos observados atualmente pelos clientes. Segundo Gomes e Vanalle (2001), os prazos e cronogramas nunca são cumpridos, o que acarreta muitos custos adicionais ao cliente, gerando forte grau de insatisfação.

Objetivando contribuir para a solução de alguns desses problemas, em outro trabalho, os autores Padilha et al. (2004) analisaram o projeto de implantação destes sistemas sob o ponto de vista do planejamento de experimentos, para identificar os fatores que exercem maior influência na determinação da duração de projeto, e sob o ponto de vista de gerenciamento do caminho crítico, buscando as atividades críticas do projeto nas quais deve ser investido para, eventualmente, reduzir a duração do projeto.

Deve-se comentar que na evolução dos Sistemas de Tecnologia de Informação, após a consolidação do $e$ business, a nova onda se refere à Colaboração nas Cadeias de Suprimentos.

Essa tendência se caracteriza pelo planejamento colaborativo entre os vários elos que compõem uma cadeia, a integração entre diversas cadeias (mesmo concorrentes, como pode ser constatado na criação em 2002 de uma empresa de distribuição cujos principais agentes são os jornais A Folha de S Paulo e o Estado de S. Paulo!) de modo que sejam melhoradas a velocidade, agilidade e a flexibilidade para o atendimento ao cliente e para a tomada de decisão.

De fato, hoje, chegou-se ao conceito de Gerenciamento da Cadeia de Valor (Value Chain Management) que é uma evolução de Gerenciamento da Cadeia de Suprimentos (Supply Chain Management) ao agregar várias cadeias (ANDRASKI, 2002). Neste estágio de evolução, falase nos novos conceitos de e-ERP e e-BI como ferramentas fundamentais para a automação da decisão e a efetiva colaboração entre os sistemas das empresas componentes das cadeias de valor envolvidas.

Deve-se comentar, ainda, que, devido às críticas aqui citadas sobre implementações tradicionais de ERP, tal como a sua inflexibilidade em não atender requisitos específicos de determinadas empresas, tem-se proposto como alternativa às empresas que desejam investir em Tecnologia de Informação o uso da "Estratégia da Melhor Criação" - BoB (Best of Breed Strategy). 
Esta estratégia consiste na integração de softwares padrões de vários fornecedores e/ou do próprio cliente, ao invés de se adotar uma solução de um único fornecedor. Por exemplo, a General Motors tem interligados o módulo Financeiro da SAP e o módulo de Recursos Humanos da Peoplesoft (ZYGMONT, 1999 apud Light et al., 2001).

Sobre esta última abordagem, Light et al. (2001) apre- sentam uma interessante análise comparativa entre utilizar um ERP (de um único fornecedor) ou optar pela estratégia de $B o B$. Estes autores ilustram, com um estudo de caso, as diferenças entre uma alternativa e outra com respeito a: complexidade de implementação, níveis de funcionalidade, potencial para o alinhamento de processos de negócios e os requisitos de manutenção.

\section{Artigo recebido em 07/08/2003 Aprovado para publicação em 29/10/2004}

\section{- Referências Bibliográficas}

AKKERMANS, H.; van HELDEN, K. Vicious and virtuous cycles in ERP implementation: a case study of interrelations between critical success factors. European Journal of Information Systems, n. 11, p. 35-46, 2002.

ANDRASKI, J. O CPFR é para todos. In: Revista Tecnologística, n. 84 , p. 34 -38 , novembro 2002.

CARDOSO, D.; SOUZA, A. Sistemas ERP: Bons para a área de produção, ruins para a área financeira. In: Encontro Nacional da Engenharia de Produção. Anais. Salvador, 2001.

CHLEBA, M. (2001). Marketing na Web, Jornal do Comércio do Rio de Janeiro. <http://www. jornaldocommercio.com.br/175anos/ br pressa/panorama 12.htm $>$. Acesso em 19 de abril de 2002.

CHOPRA, S.; MEINDL, P. Gerenciamento da Cadeia de Suprimentos - Estratégia, Planejamento e Operação. Prentice Hall, 2003.

COMPUTERWORLD. 100 Maiores de Informática 1998/99. IDG Computerworld do Brasil Serviços e Publicações Ltda. 1999.

COMPUTERWORLD. Investimentos em $\mathrm{TI}$ caem $10 \%$ nos Estados Unidos. Disponível na Internet em <http//: www. Computerworld.com. br $>$. Acesso em 10/ novembro/2001.
COMPUTERWORLD. Cresce a venda de Veículos Ford pela Internet. Disponível na Internet em < http//: www. Computerworld.com. br $>$. Acesso em 29/setembro/03.

CORRÊA, H. L.; GIANESI, I.G.N.; CAON, M. Planejamento, Programação e Controle da Produção. 2.ed. Editora Atlas, 1999.

DAVENPORT, T.H. Putting the Enterprise into the Enterprise System. Harvard Business Review, p. 121-131, Jul/Aug. 1998.

GED, A. Mundo integrado ao ERP. Mundo da Imagem, n. 36, p. 2-6, nov./ dez. 1999.

GOMES, C.; VANALLE, R. Aspectos Críticos para a Implantação de Sistemas ERP. In: Encontro Nacional da Engenharia de Produção. Anais. Salvador, 2001.

HAMMER, M.; CHAMPY, J. Reengenharia: repensando a empresa em função dos clientes, da concorrência e das grandes mudanças da gerenciar. 1.ed. Rio de Janeiro: Ed. Campus, 1994.

$\mathrm{KOCH}, \mathrm{C} . \mathrm{BPR}$ and ERP: realizing a vision of process with IT. Business Process Management Journal, v. 7, n. 3 , p. $258-265,2001$
KOCH, C.; SLATER, D.; BAATZ, E. The ABCs of ERP. Disponível na Internet em < http://www.cio.com>. Acesso em 22/agosto/2001.

LIGHT, B.; HOLLAND, C.P. ; WILLS, K. ERP and Best of Breed: a comparative analysis. Business Process Management Journal, v. 7, n. 3, p. 216-224, 2001

MARTINS, V.; BREMER, C.F. Proposta de uma ferramenta de integração entre sistemas ERP-SCADA: Caso Prático. In: Encontro Nacional de Engenharia de Produção. Anais. Curitiba, 2002.

NAH, F.F.-H.; LAU, J.L.-S.; KUANG, J. Critical factors for successful implementation of enterprise systems. Business Process Management Journal, v. 7, n. 3, p. 285-296, 2001.

OGURA, A. K.; MARINS, F. A. S. Uma Abordagem para Modelagem de Processos através de um ERP. In: Encontro Nacional de Engenharia de Produção. Anais. Ouro Preto, 2003.

OLIVEIRA, M.A., RAMOS, A.S.M. Fatores de Sucesso na Implementação de Sistemas Integrados de Gestão Empresarial (ERP): Estudo de Caso em uma Média Empresa. In: Encontro Nacional de Engenharia de Produção. Anais. Curitiba, 2002
PADILHA, T.C.C.; COSTA, A.F.B; CONTADOR, J.L.; MARINS, F.A.S. Tempo de Implantação de Sistemas ERP: análise da influência de fatores e aplicação de técnicas de gerenciamento de projetos. Gestão \& Produção, v. 11, n. 1, p. 65-74, 2004

ROZENFELD, H. Integração de Empresas - CIM. Disponível em <http:// www.numa.org.br $>$. Acesso em maio de 2002.

SAUTER, V. Decision Support Systems: An Applied Managerial Application. 1.ed. New York: IE-Wiley,1996.

SCHEER, A. W. Aris - Business Process Framework. 2 ed. Berlim: Springer Verlag, 1998.

SCHEER, A.W.; HABERMANN F. Making a ERP Success. Association for Computing Machinery Communications of the ACM New York, Apr 2000, p. 57-61.

STAIR, R.M. Princípios de Sistemas de Informação: uma Abordagem Gerencial. 2.ed. São Paulo: Editora LTC, 1998.

VERNADAT, F.B. Enterprise Modeling and Integration: Principles and Applications. 1.ed. London: Chapman \& Hall, 1996.

WAGLE, D. The Case for ERP Systems. The Mckinsey Quarterly, n. 2, 1998, p. 130-138.

h t t p : // h e l p.s a p.com saphelp srm30/helpdata/en/95/ f6a93e $08 \overline{5} 03614 \mathrm{e} 10000000 \mathrm{a} 114084 /$ frameset.htm, acesso em 23 de março de 2004 .

\section{- Sobre os autores}

\section{Thais Cássia Cabral Padilha}

Oracle do Brasil

Consultora ERP Service Line

R. Novo Cancioneiro 60 - CEP 04704 - 080 - São Paulo - SP

Tel: 11 5189-3030 / 11 9676-7515 Email: thais.padilha@ oracle.com

\section{Fernando Augusto Silva Marins}

Faculdade de Engenharia - Campus de Guaratinguetá - UNESP

Professor Adjunto

Av. Ariberto Pereira da Cunha, 333, CEP 12516-410 - Guaratinguetá - SP

Tel/Fax: 1231232855 E-mail: fmarins@feg.unesp.br 